\title{
A mesoscale-structure-dependent EMMS drag model for SCW fluidized bed: Formulation of conservation equations based on structures in subphases
}

By

\section{Hao Wang, Youjun Lu*}

State Key Laboratory of Multiphase Flow in Power Engineering,

$X i$ 'an Jiaotong University, Xi'an 710049, Shaanxi, China

\section{Supporting Information for Publication}

* Corresponding author. Tel.:+86-29-82664345; fax: +86-29-8266-9033

E-mail: yjlu@mail.xjtu.edu.cn (Youjun Lu) 


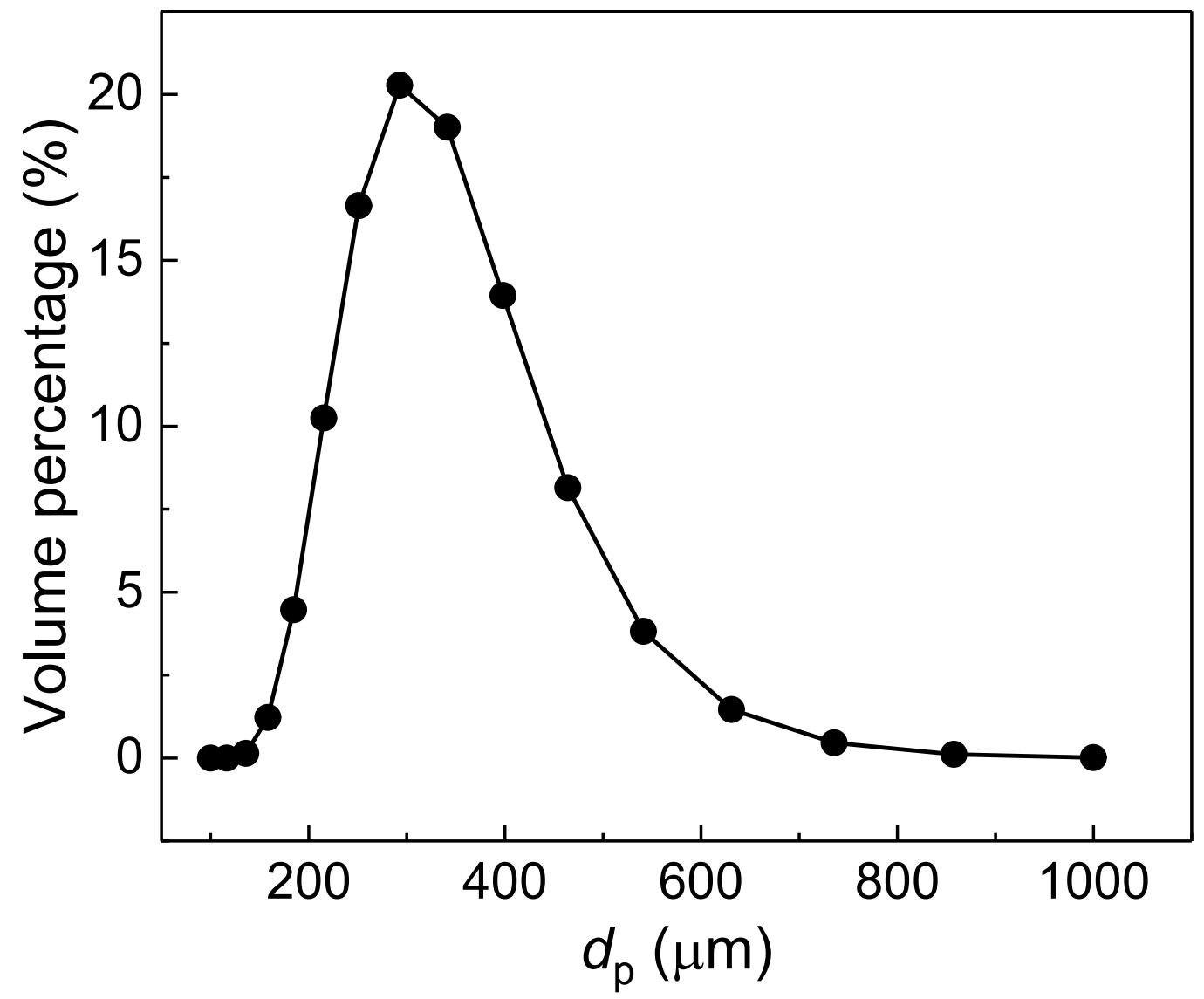

Figure S 1. Particle size distribution of quartz sand. 
It can be shown by Eq. (1) that the virtual mass force (F), for a bubble submerged in an inviscid, incompressible emulsion phase is: ${ }^{1}$

$$
\mathbf{F}=\frac{\rho_{\mathrm{e}} V_{\mathrm{b}}}{2}\left(\frac{\mathrm{d} \mathbf{u}_{\mathrm{e}}}{\mathrm{d} t}-\frac{\mathrm{d} \mathbf{u}_{\mathrm{b}}}{\mathrm{d} t}\right)
$$

where bold symbols denote vectors, $\mathbf{u}_{\mathrm{e}}$ is the flow velocity of the emulsion phase, $\mathbf{u}_{\mathrm{b}}$ is the bubble velocity, $\rho_{\mathrm{e}}$ is the mass density of the emulsion phase, $V_{\mathrm{b}}$ is the volume of the bubble.

In this study, the velocity of emulsion is constant. Therefore, Eq. (1) can be rearranged by:

$$
\mathbf{F}=-\frac{1}{2} \rho_{\mathrm{e}}\left(\frac{1}{6} \pi d_{\mathrm{b}}^{2}\right) a_{\mathrm{b}}
$$

where $d_{\mathrm{b}}$ is bubble size, $a_{\mathrm{b}}$ is bubble acceleration.

The number density of bubbles $\left(m_{\mathrm{i}}\right)$ reads:

$$
m_{\mathrm{i}}=f_{\mathrm{b}} /\left(\frac{\pi}{6} d_{\mathrm{b}}^{3}\right)
$$

Then the Eq. (2) can be rearranged by combining Eq. (3):

$$
m_{\mathrm{i}} \mathbf{F}=-f_{\mathrm{b}} \frac{1}{2} \rho_{\mathrm{e}} a_{\mathrm{b}}
$$

Therefore, the expression of virtual mass force in Eq. (4) is consistent with that in the manuscript. 

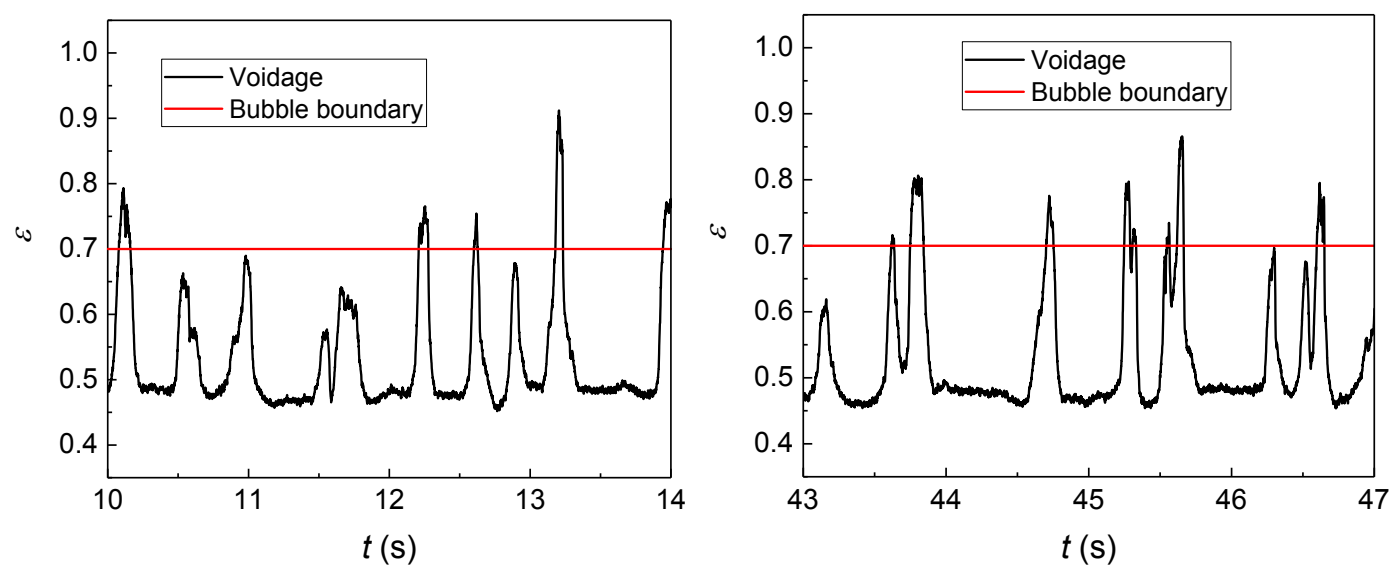

(a)

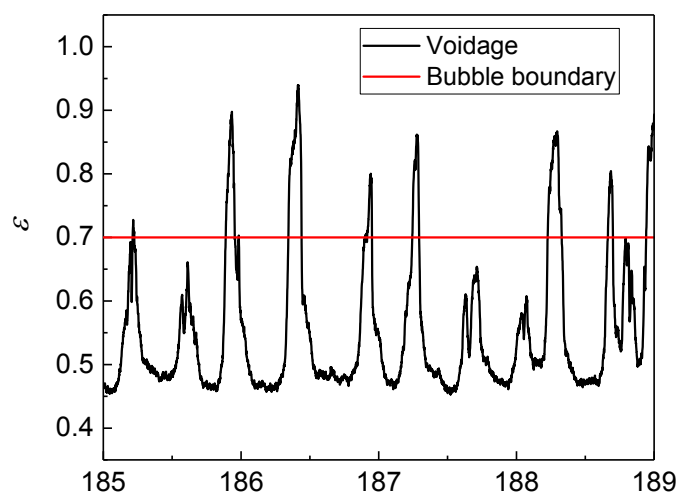

(b)

$t$ (s)

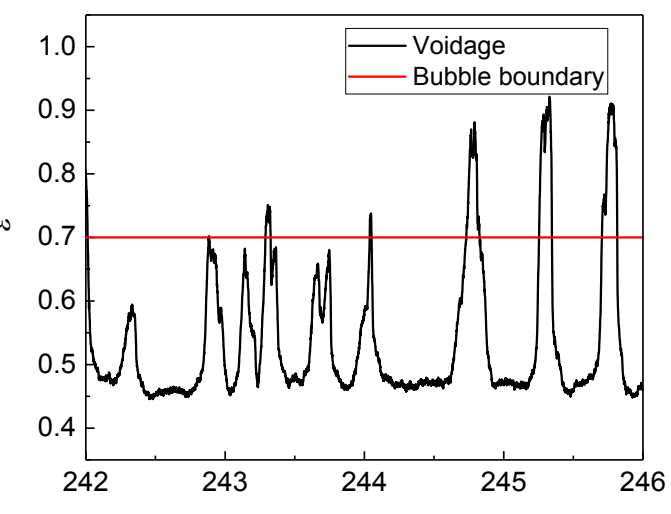

$t$ (s)

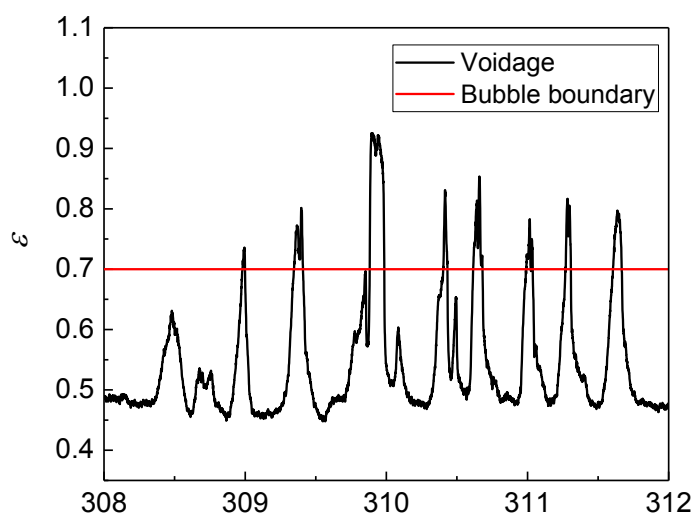

(c)

$t$ (s)

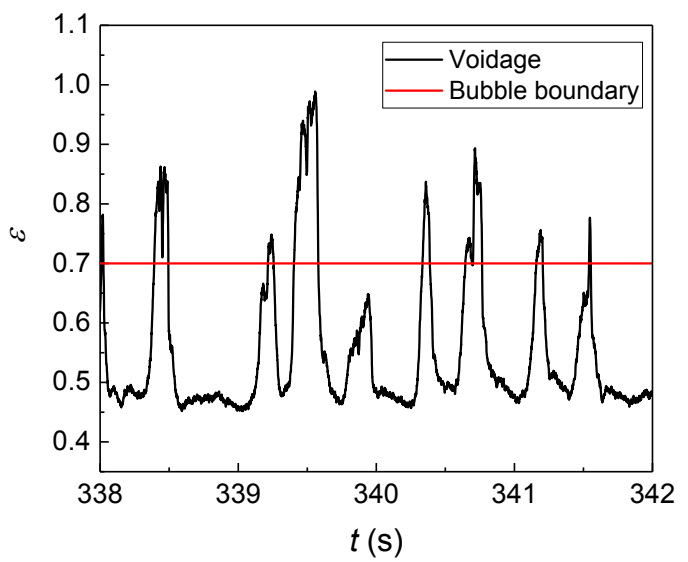



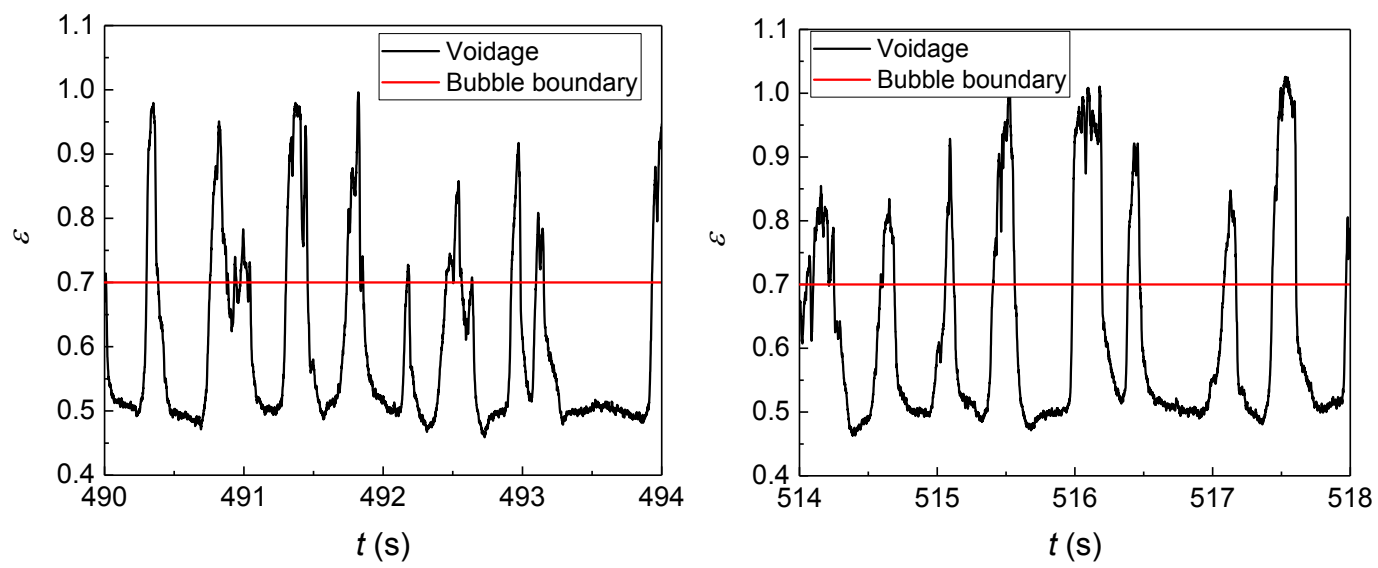

Figure S 2. Fluctuations of time-series of local voidage at $r / \mathrm{R}=0$ : (a) $U_{\mathrm{f}}=0.050 \mathrm{~m} / \mathrm{s}$; (b) $U_{\mathrm{f}}$ $=0.061 \mathrm{~m} / \mathrm{s} ;$ (c) $U_{\mathrm{f}}=0.070 \mathrm{~m} / \mathrm{s} ;$ (d) $U_{\mathrm{f}}=0.083 \mathrm{~m} / \mathrm{s}$. 


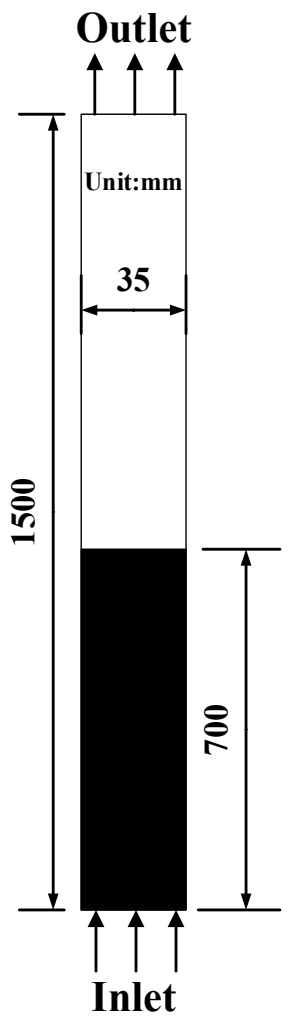

Figure $\mathbf{S} 3$. The geometry of the SCW fluidized bed. 
In this manuscript, 2D simulations are used for a 3D system. Empirical correlations developed from the 3D SCW fluidized beds are applied to validate the results of the MSD-EMMS model. Because of the high-temperature and -pressure SCW, it is impossible to study the fluidization behaviors in a $2 \mathrm{D}$ bed.

Based on the discussion below, the explanation and justification the usage of a 2D simulation for a 3D system can be concluded:

1) Comparison studies of $2 \mathrm{D}$ and $3 \mathrm{D}$ correlations show that bubbles hydrodynamics for $d_{\mathrm{b}}$ less than $35 \mathrm{~mm}$ are comparable for the SCW fluidized bed.

2) Comparison studies of $2 \mathrm{D}$ and $3 \mathrm{D}$ simulations in the literature indicate that bubbles hydrodynamics of 2D simulations show promising agreement with 3D results and 3D empirical correlations.

3) The time-averaged characteristics of $2 \mathrm{D}$ planes through the axis of rotation of a $3 \mathrm{D}$ cylindrical tube should be the same.

Firstly, we compared empirical correlations based on 2D and 3D gas-solid fluidization experiments. A correlation between bubble diameters $\left(d_{\mathrm{b}}\right)$ and velocities $\left(U_{\mathrm{b}}\right)$ based on 3D fluidized beds was recommended by Davidson and Harrison, ${ }^{2}$ which can be expressed by:

$$
U_{\mathrm{b}}=\left(U_{\mathrm{f}}-U_{\mathrm{mf}}\right)+0.71 \sqrt{\mathrm{g} d_{\mathrm{b}}}
$$

Shen, et al..$^{3}$ studied hydrodynamics in a 2D bubbling fluidized bed and proposed a correlation $d_{\mathrm{b}}$ and $U_{\mathrm{b}}$ in using digital image analysis, which is given by:

$$
U_{\mathrm{b}}=\phi \sqrt{\mathrm{g} d_{\mathrm{b}}}(\phi=0.8-1.0)
$$

Where $U_{\mathrm{mf}}$ is the minimum fluidization velocity, which is proposed by Lu, et al. ${ }^{4}$.

2D and 3D correlations between bubble diameters $\left(d_{\mathrm{b}}\right)$ and distance from the distributor $(H)$ are 
compared. Cranfield and Geldart ${ }^{5}$ proposed a correlation between $d_{\mathrm{b}}$ and $H$ for a 3D bubbling fluidized bed, which is read:

$$
d_{\mathrm{b}}=0.0326\left(U_{\mathrm{f}}-U_{\mathrm{mf}}\right)^{1.11} H^{0.81}
$$

In the 2D experimental work of Shen, Johnsson and Leckner ${ }^{3}$, a correlation between $d_{\mathrm{b}}$ and $H$ is also proposed:

$$
d_{\mathrm{b}}=0.89\left[\left(U_{\mathrm{f}}-U_{\mathrm{mf}}\right)\left(H+3.0 A_{0} / \delta\right)\right]^{2 / 3} / \mathrm{g}^{1 / 3}
$$

The comparison between the 3D and 2D correlations of bubble velocities and bubble diameters can be seen in Figure S 4 and Figure S 5 respectively. It can be seen from Figure S 4 that the differences between 3D and 2D correlations are not obvious for $d_{\mathrm{b}}$ less than $35 \mathrm{~mm}$. Similar conclusions can be drawn from Figure S 5 that the bubble diameters calculated by 3D and 2D correlations are close. It means that bubble hydrodynamics in 3D and 2D fluidized beds are close especially for small bubbles ( $d_{\mathrm{b}}$ less than $35 \mathrm{~mm}$ ). The diameters of bubbles in SCW fluidized beds are less than the inner diameter of fluidized bed $(35 \mathrm{~mm})$. Therefore, bubbles hydrodynamics in $2 \mathrm{D}$ and $3 \mathrm{D}$ cases should be comparable for the SCW fluidized bed of this paper.

Secondly, in the experimental study of the 2D bubbling fluidized bed of Busciglio, et al., ${ }^{6}$ the bubble diameters have good agreement with the 3D correlation of Darton, et al.. ${ }^{7}$ In the comparative studies of 2D and 3D simulations of Cammarata, et al. ${ }^{8}$ and Wang, et al., ${ }^{9}$ the bubble diameters of 2D simulations show promising agreement with 3D results and empirical correlations based on 3D experimental data. Therefore, it can be concluded that the 2D simulations can be applied to $3 \mathrm{D}$ fluidized beds.

At last, a 3D cylindrical tube was applied for experimental work, which is an axial rotating symmetry. In general, the instantaneous fluidization characteristics in the plane through the axis of 
rotation are different, while the time-averaged characteristics should be the same. Therefore, 2D simulations were enough for time-averaged bubble hydrodynamics (e.g. bubble size and velocity) and validation of the results from the MSD-EMMS drag model. 

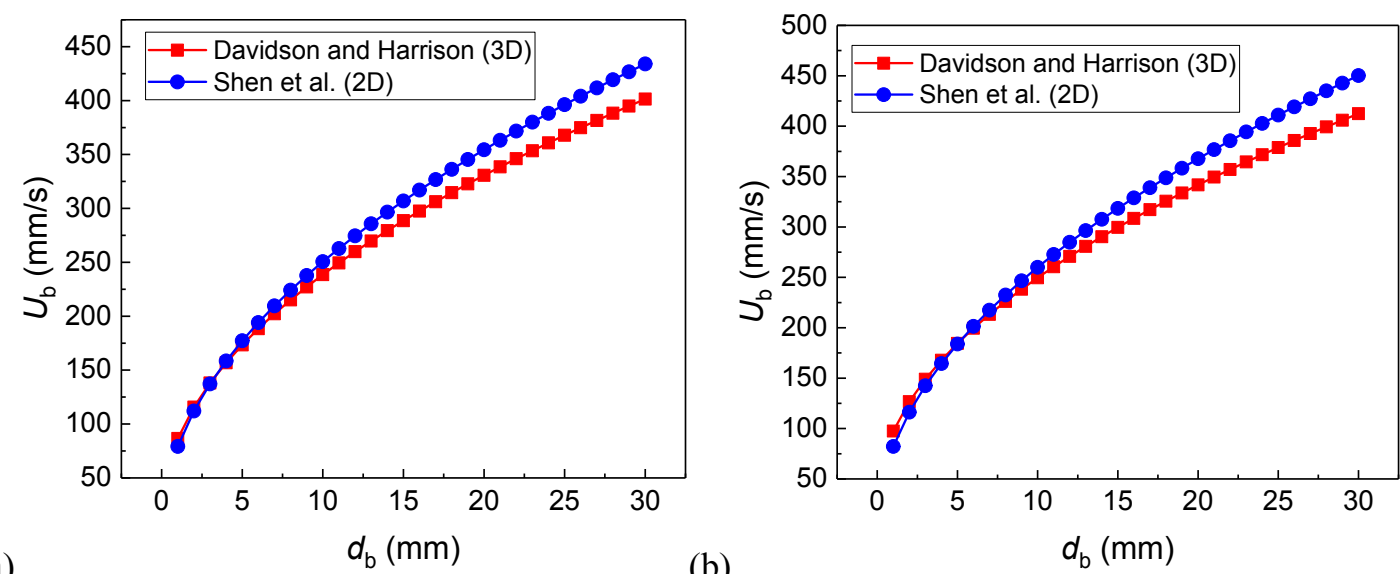

(a)

(b)
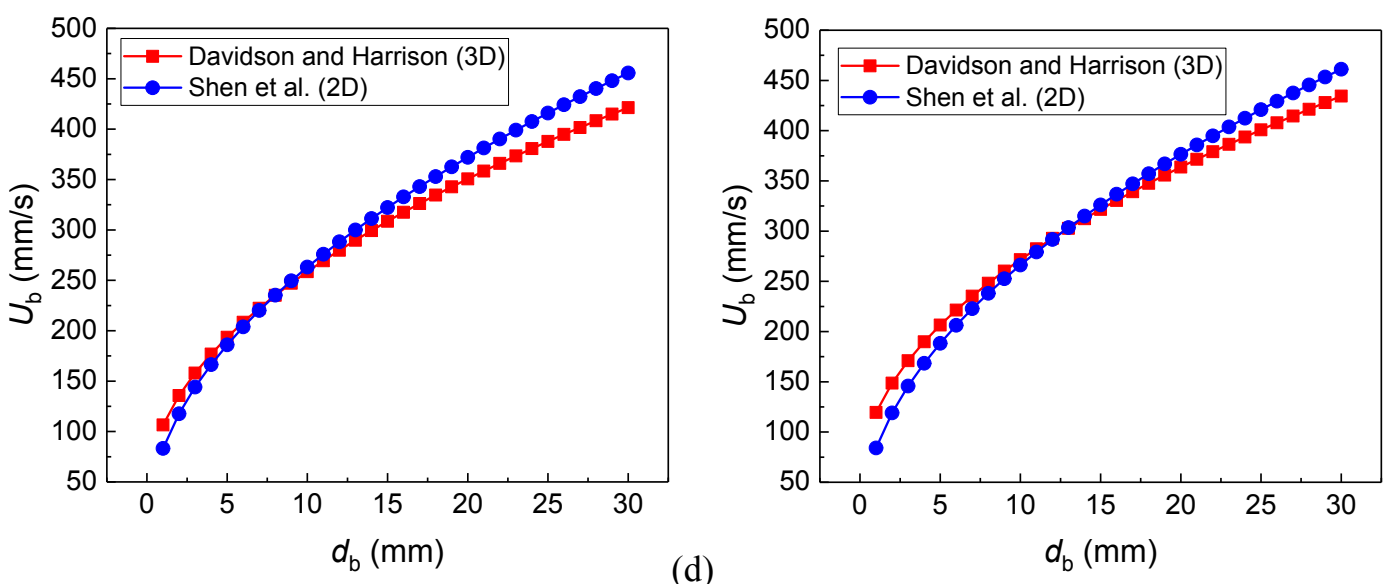

Figure S 4. Comparison between the 3D (Davidson and Harrison ${ }^{2}$ ) and 2D (Shen, Johnsson and

Leckner $^{3}$ ) correlations of bubble velocities: (a) $U_{\mathrm{f}}=0.050 \mathrm{~m} / \mathrm{s}$; (b) $U_{\mathrm{f}}=0.061 \mathrm{~m} / \mathrm{s}$; (c) $U_{\mathrm{f}}$

$$
=0.070 \mathrm{~m} / \mathrm{s} ; \text { (d) } U_{\mathrm{f}}=0.083 \mathrm{~m} / \mathrm{s} \text {. }
$$



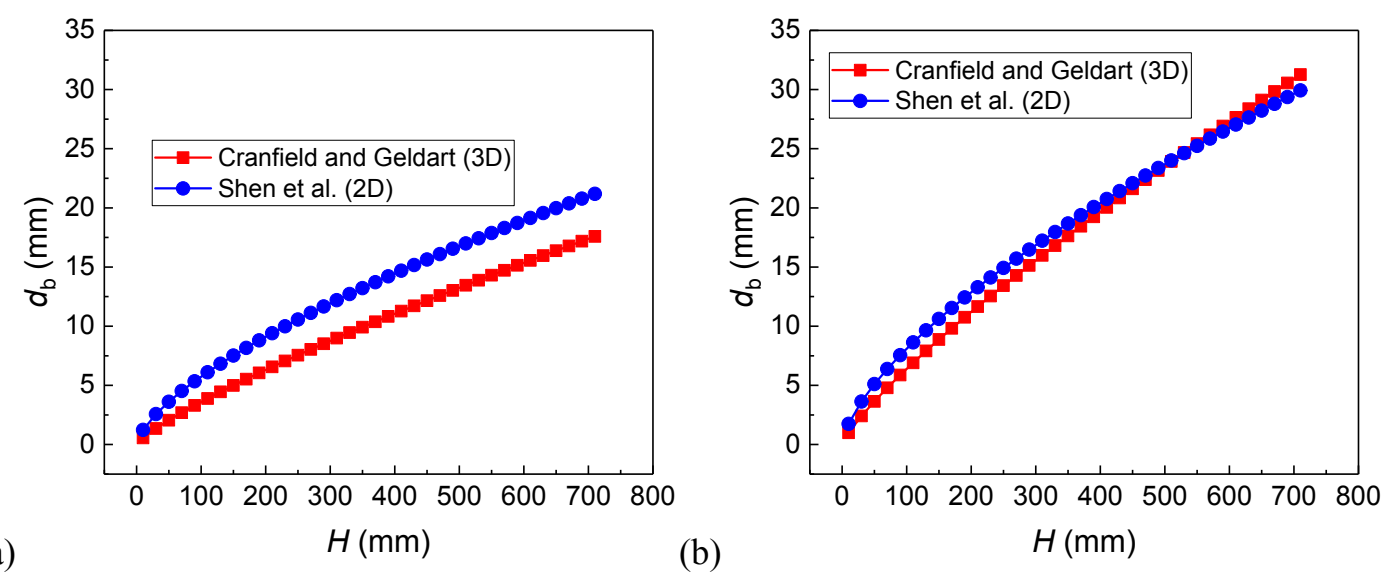

(a)

(b)

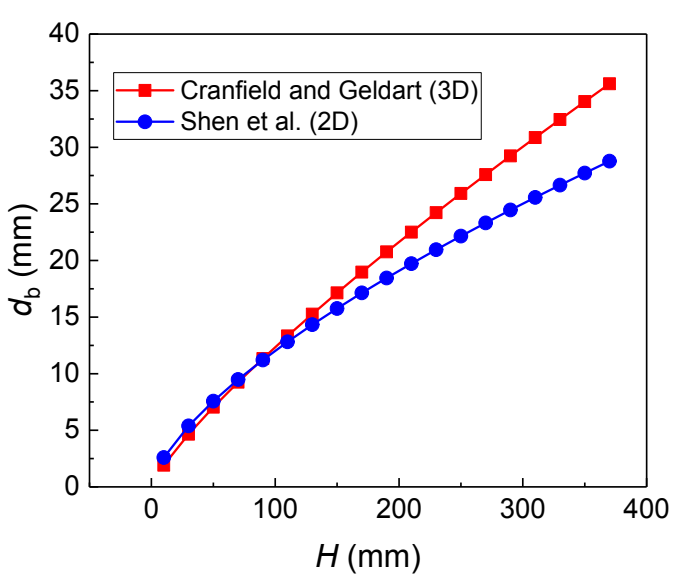

(c)

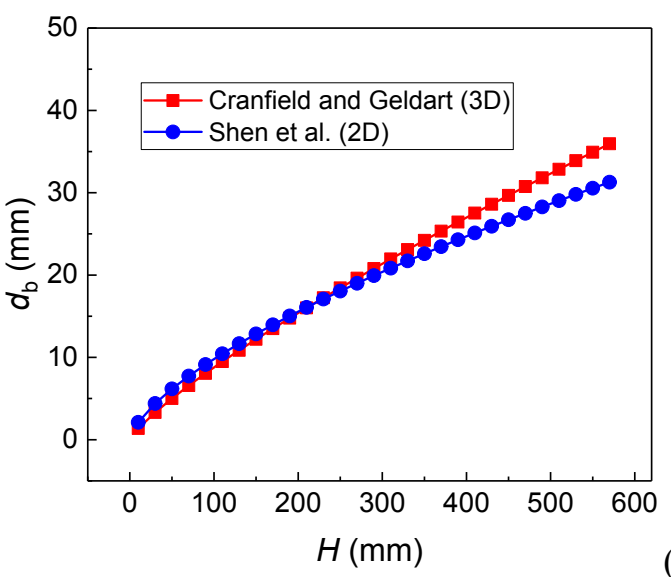

(d)

Figure S 5. Comparison between the 3D (Cranfield and Geldart $\left.{ }^{5}\right)$ and 2D (Shen, Johnsson and

Leckner $^{3}$ ) correlations of bubble diameters: (a) $U_{\mathrm{f}}=0.050 \mathrm{~m} / \mathrm{s}$; (b) $U_{\mathrm{f}}=0.061 \mathrm{~m} / \mathrm{s}$; (c) $U_{\mathrm{f}}$

$$
=0.070 \mathrm{~m} / \mathrm{s} ;(\mathrm{d}) U_{\mathrm{f}}=0.083 \mathrm{~m} / \mathrm{s} \text {. }
$$


The simulation results of the Gidaspow drag model at $U_{\mathrm{f}}=0.070 \mathrm{~m} / \mathrm{s}$ with 25000 grids were simulated and the comparison results of bubble velocities distribution are shown in Figure S 6. It can be seen in Figure S 6 that the simulation results of larger bubbles with 25000 grids have better agreement with empirical correlation than 8400 grids. However, from an overall perspective, the performance of simulation with 25000 grids on predicting bubble velocities distribution is worse than that with 8400 grids.

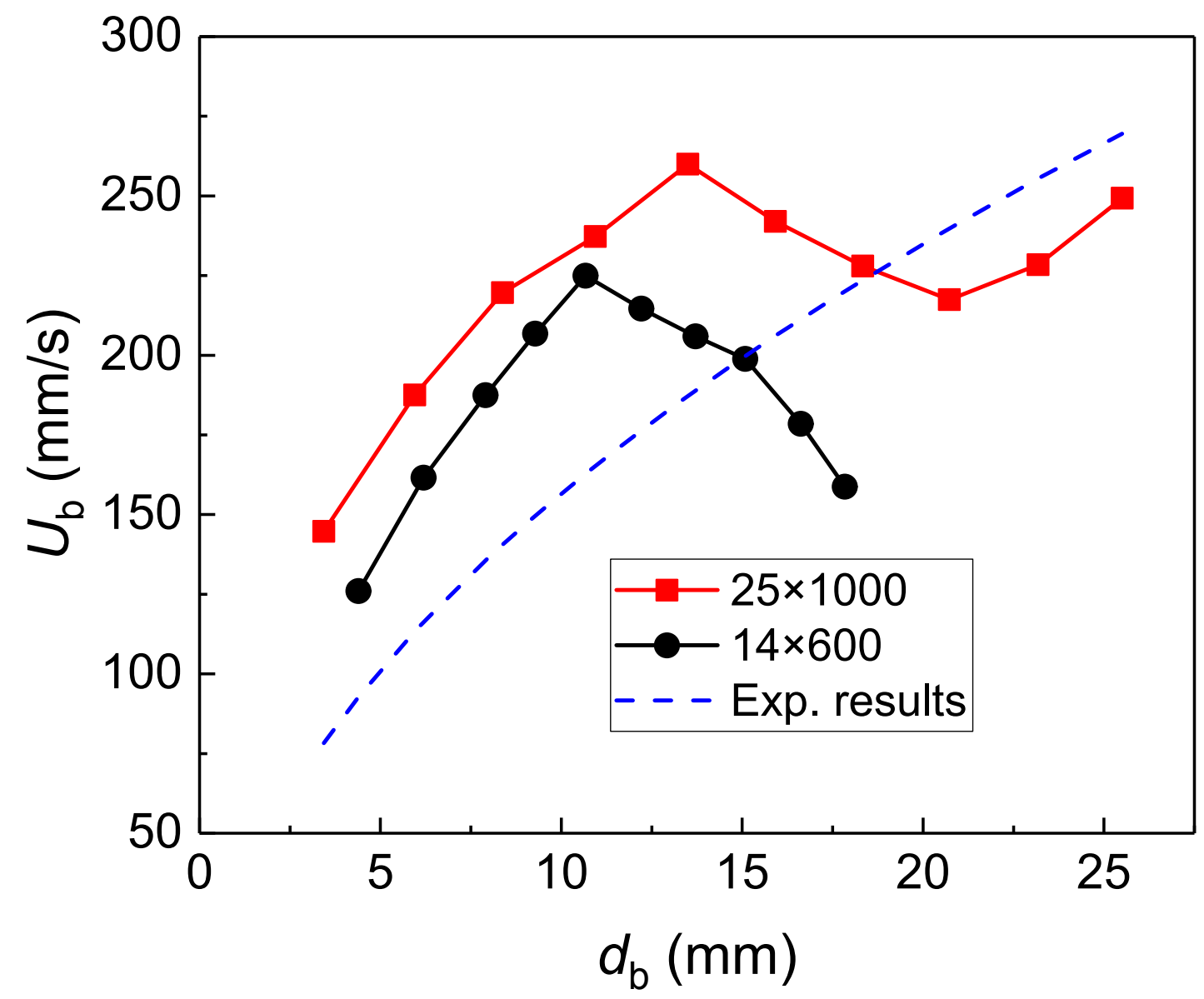

Figure S 6. Comparison of bubble velocity distribution between simulation of Gidasopw model with different grid numbers and empirical correlation at $U_{\mathrm{f}}=0.070 \mathrm{~m} / \mathrm{s}$. 
The sensitivity analysis of threshold voidage is present in Figure S 7. It can be seen from Figure S 7 that a slight difference between the results of three threshold values was found, which may indicate that the effect of threshold voidage is not significant. Therefore, it is reasonable that voidage of 0.7 is selected to be the threshold value.

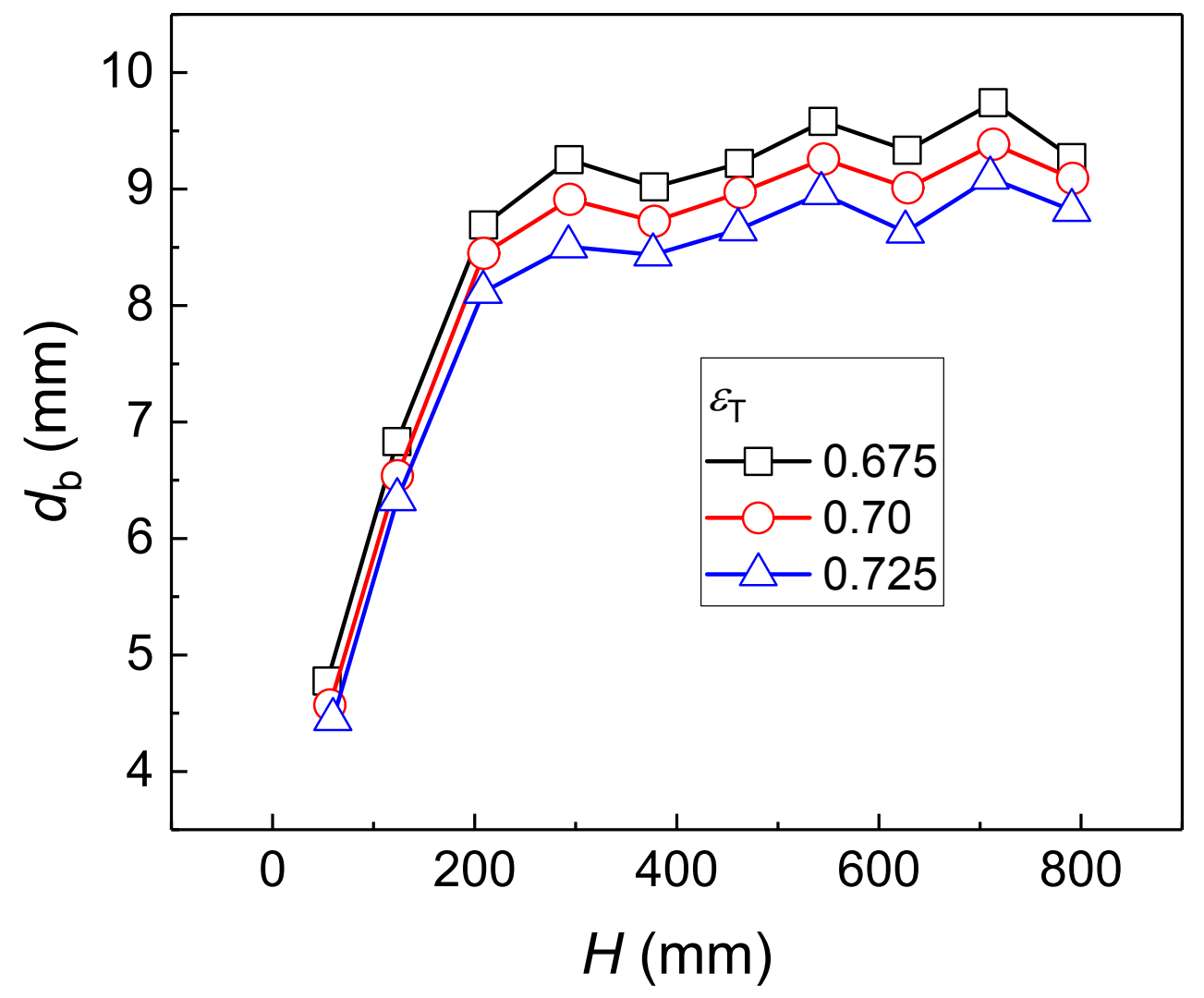

Figure S 7. The effect of threshold value of voidage on averaged bubble diameter using Gidasopw model at $U_{\mathrm{f}}=0.070 \mathrm{~m} / \mathrm{s}$. 
The data in Figure 6 was derived from voidage information of fluidization. To make the data more intuitive, the snapshots of predicted solids fraction at $U_{\mathrm{f}}=0.061 \mathrm{~m} / \mathrm{s}$ are shown in Figure $\mathrm{S}$ 8. In the first second, it can be seen from Figure S 8 that particles in the upper bed maintain unfluidized for the Gidasopw model while the solid phase starts to be fluidized using EMMS approaches. Therefore, particles are fluidized more quickly in using EMMS approaches than the Gidaspow model.

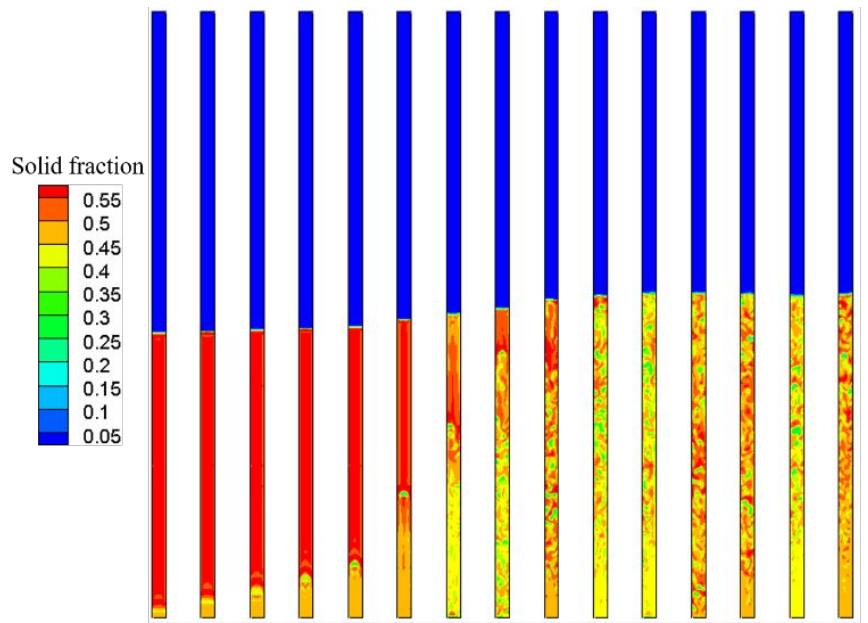

(a)
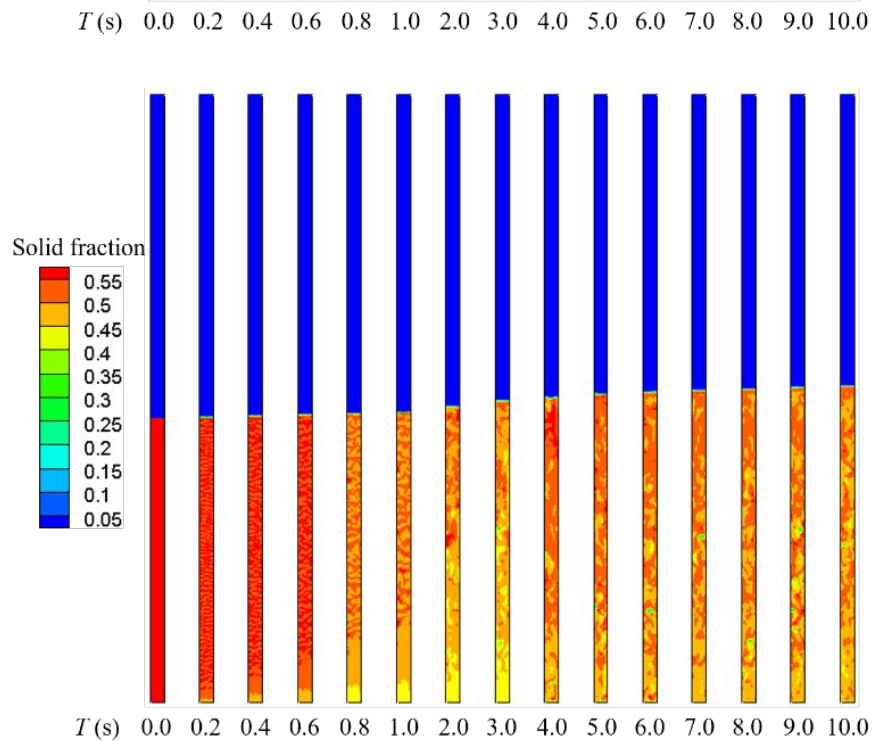

(b) 


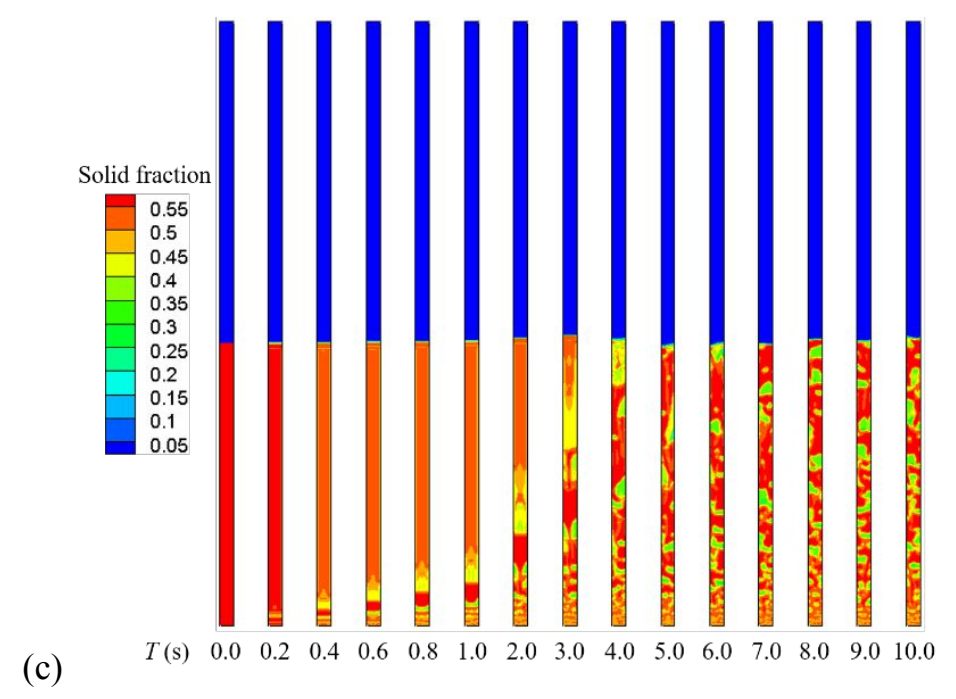

Figure S 8. Snapshots of predicted solids fraction at $U_{\mathrm{f}}=0.061 \mathrm{~m} / \mathrm{s}$ : (a) Gidaspow model; (b) EMMS/bubbling model; (c) MSD-EMMS model. 
The frequency distribution of bubble velocities for drag models is shown in Figure S 9. It can be seen from Figure $\mathrm{S} 9$ that the frequency distribution of bubble velocities is not normal. The amount of bubbles with low velocity is larger than ones with high velocity. This is reasonable because the number of small bubbles in the bed is greater than large bubbles. Besides, small bubbles have lower velocities than large bubbles. Therefore, more bubbles with low velocity are generated.
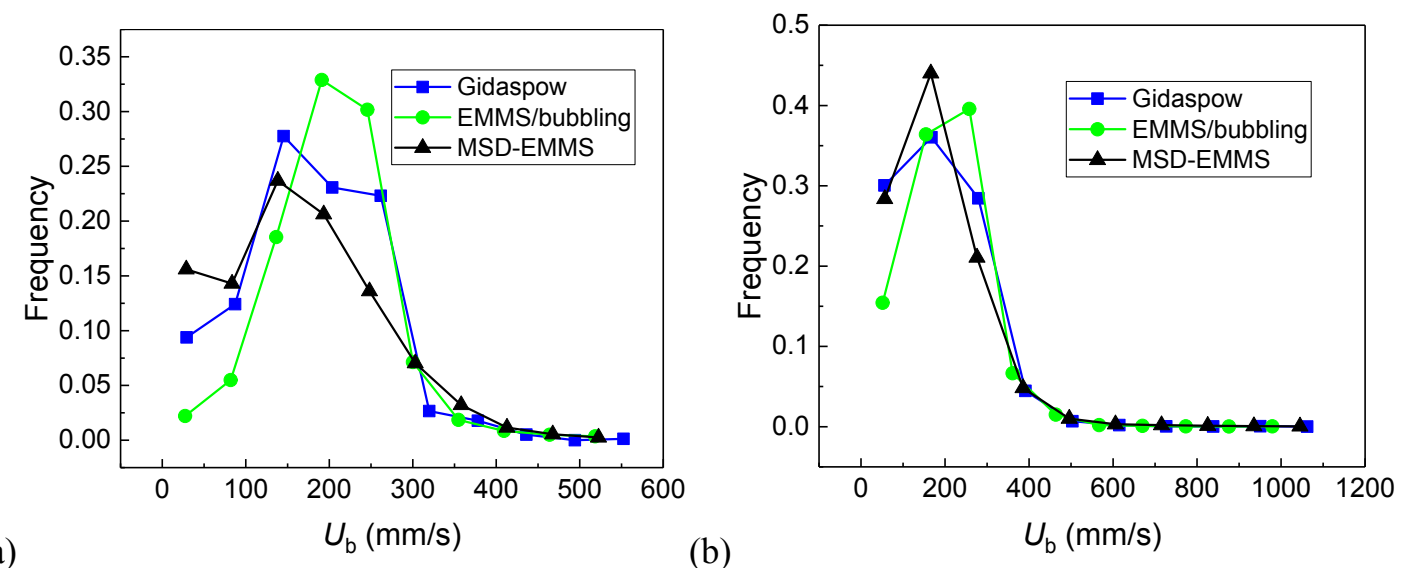

(a)

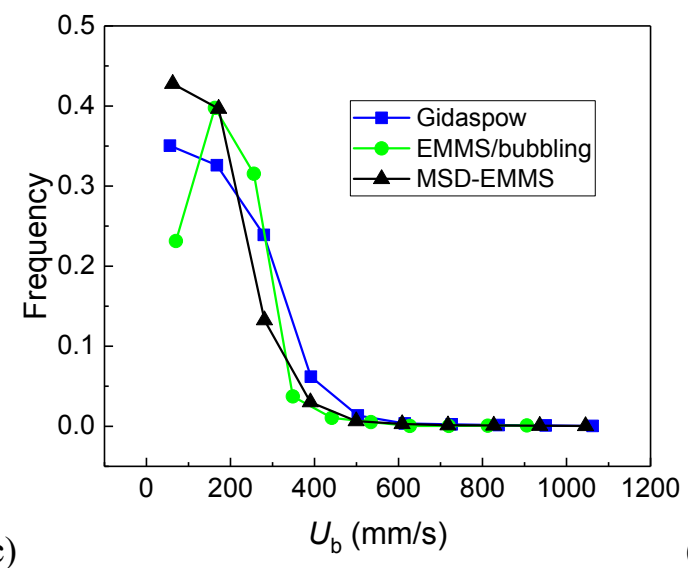

(b)

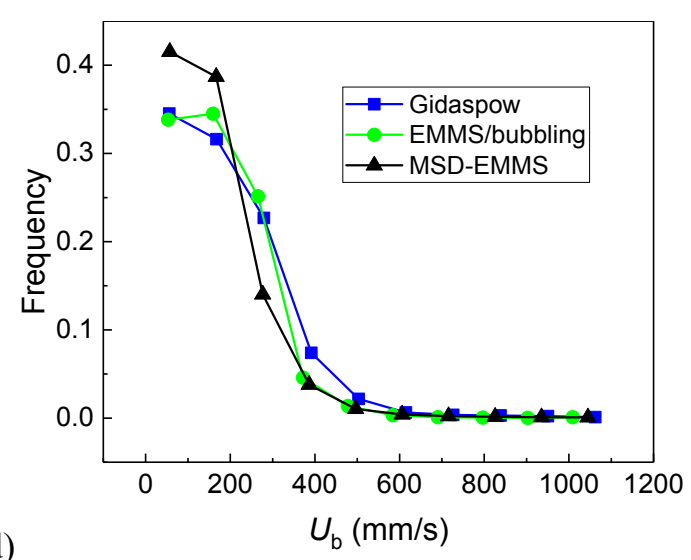

Figure S 9. Frequency distribution of bubble velocities for drag models: (a) $U_{\mathrm{f}}=0.050 \mathrm{~m} / \mathrm{s}$; (b)

$$
U_{\mathrm{f}}=0.061 \mathrm{~m} / \mathrm{s} \text {; (c) } U_{\mathrm{f}}=0.070 \mathrm{~m} / \mathrm{s} ; \text { (d) } U_{\mathrm{f}}=0.083 \mathrm{~m} / \mathrm{s} \text {. }
$$


Table S 1. The constitutive equation of the kinetic theory of granular flow (KTGF)

Mass conservation of fluid and particles:

$$
\begin{aligned}
& \frac{\partial}{\partial t}\left(\varepsilon_{\mathrm{f}} \rho_{\mathrm{f}}\right)+\nabla \cdot\left(\varepsilon_{\mathrm{f}} \rho_{\mathrm{f}} \mathbf{u}_{\mathrm{f}}\right)=0 \\
& \frac{\partial}{\partial t}\left(\varepsilon_{\mathrm{p}} \rho_{\mathrm{p}}\right)+\nabla \cdot\left(\varepsilon_{\mathrm{p}} \rho_{\mathrm{p}} \mathbf{u}_{\mathrm{p}}\right)=0
\end{aligned}
$$

Momentum conservation of fluid and particles:

$$
\begin{aligned}
& \frac{\partial}{\partial t}\left(\varepsilon_{\mathrm{p}} \rho_{\mathrm{p}} \mathbf{u}_{\mathrm{p}}\right)+\nabla \cdot\left(\varepsilon_{\mathrm{p}} \rho_{\mathrm{p}} \mathbf{u}_{\mathrm{p}} \mathbf{u}_{\mathrm{p}}\right)=-\varepsilon_{\mathrm{p}} \nabla p-\nabla p_{\mathrm{p}}+\nabla \cdot \tau_{\mathrm{p}}+\varepsilon_{\mathrm{p}} \rho_{\mathrm{p}} \mathrm{g}+\beta\left(\mathbf{u}_{\mathrm{f}}-\mathbf{u}_{\mathrm{p}}\right) \\
& \frac{\partial}{\partial t}\left(\varepsilon_{\mathrm{f}} \rho_{\mathrm{f}} \mathbf{u}_{\mathrm{f}}\right)+\nabla \cdot\left(\varepsilon_{\mathrm{f}} \rho_{\mathrm{f}} \mathbf{u}_{\mathrm{f}} \mathbf{u}_{\mathrm{f}}\right)=-\varepsilon_{\mathrm{f}} \nabla p+\nabla \cdot \tau_{\mathrm{f}}+\varepsilon_{\mathrm{f}} \rho_{\mathrm{f}} \mathrm{g}-\beta\left(\mathbf{u}_{\mathrm{f}}-\mathbf{u}_{\mathrm{p}}\right)
\end{aligned}
$$

Granular temperature equation:

$$
\frac{3}{2}\left[\frac{\partial}{\partial t}\left(\varepsilon_{\mathrm{p}} \rho_{\mathrm{p}} \Theta_{\mathrm{p}}\right)+\nabla \cdot\left(\varepsilon_{\mathrm{p}} \rho_{\mathrm{p}} \mathbf{u}_{\mathrm{p}} \Theta_{\mathrm{p}}\right)\right]=\left(-p_{\mathrm{p}} \mathbf{I}+\tau_{\mathrm{p}}\right): \nabla \mathbf{u}_{\mathrm{p}}+\nabla\left(k_{\mathrm{p}} \nabla \Theta_{\mathrm{p}}\right)-\gamma_{\mathrm{p}}-3 \beta \Theta_{\mathrm{p}}
$$

Stress for fluid

$$
\tau_{\mathrm{f}}=\mu_{\mathrm{f}}\left[\nabla \mathbf{u}_{\mathrm{f}}+\left(\nabla \mathbf{u}_{\mathrm{f}}\right)^{\mathrm{T}}\right]-\frac{2}{3} \mu_{\mathrm{f}} \nabla \cdot \mathbf{u}_{\mathrm{f}}
$$

Stress for particles

$$
\tau_{\mathrm{p}}=\mu_{\mathrm{p}}\left[\nabla \mathbf{u}_{\mathrm{p}}+\left(\nabla \mathbf{u}_{\mathrm{p}}\right)^{\mathrm{T}}\right]+\left(\lambda_{\mathrm{p}}-2 / 3 \mu_{\mathrm{p}}\right) \nabla \cdot \mathbf{u}_{\mathrm{p}}
$$

Radial distribution function

$$
g_{0}=\left[1-\left(\varepsilon_{\mathrm{p}} / \varepsilon_{\mathrm{p}, \max }\right)^{1 / 3}\right]^{-1}
$$

Solid pressure

$$
p_{\mathrm{p}}=\varepsilon_{\mathrm{p}} \rho_{\mathrm{p}} \Theta_{\mathrm{p}}+2(1+e) \varepsilon_{\mathrm{p}}^{2} g_{0} \rho_{\mathrm{p}} \Theta_{\mathrm{p}}
$$

Bulk solid viscosity

$$
\lambda_{\mathrm{p}}=\frac{4}{3} \varepsilon_{\mathrm{p}} \rho_{\mathrm{p}} d_{\mathrm{p}} g_{0}(1+e)\left(\frac{\Theta_{\mathrm{p}}}{\pi}\right)^{1 / 2}
$$

Shear viscosity of particles 
$\mu_{\mathrm{p}}=\mu_{\mathrm{p}, \mathrm{kin}}+\mu_{\mathrm{p}, \mathrm{col}}+\mu_{\mathrm{p}, \mathrm{fr}}$

Overall

$\mu_{\mathrm{p}}=10 \rho_{\mathrm{p}} d_{\mathrm{p}} \frac{\sqrt{\Theta_{\mathrm{p}} \pi}}{96 \varepsilon_{\mathrm{p}}(1+e) \varepsilon_{\mathrm{p}} g_{0}}\left[1+\frac{4}{5}(1+e) \varepsilon_{\mathrm{p}} g_{0}\right]^{2}+\frac{4}{5}(1+e) \varepsilon_{\mathrm{p}} g_{0} \rho_{\mathrm{p}} d_{\mathrm{p}}\left(\frac{\Theta_{\mathrm{p}}}{\pi}\right)^{1 / 2}+\frac{p_{\mathrm{p}} \sin \phi}{2 \sqrt{I_{2 \mathrm{D}}}}$

Granular conductivity of fluctuation energy

$k_{\mathrm{p}}=\frac{150 \rho_{\mathrm{p}} d_{\mathrm{p}}\left(\Theta_{\mathrm{p}} \pi\right)^{1 / 2}}{384(1+e) g_{0}}\left[1+\frac{6}{5}(1+e) \varepsilon_{\mathrm{p}} g_{0}\right]^{2}+2(1+e) \varepsilon_{\mathrm{p}}^{2} g_{0} \rho_{\mathrm{p}} d_{\mathrm{p}}\left(\frac{\Theta_{\mathrm{p}}}{\pi}\right)^{1 / 2}$

Collisional energy dissipation

$\gamma_{\mathrm{p}}=3\left(1-e^{2}\right) \varepsilon_{\mathrm{p}}^{2} g_{0} \rho_{\mathrm{p}} \Theta_{\mathrm{p}}\left[\frac{4}{d_{\mathrm{p}}}\left(\frac{\Theta_{\mathrm{p}}}{\pi}\right)^{1 / 2}\right]$

Drag coefficient of Gidaspow model:

$\beta_{\text {Gidaspow }}=\left\{\begin{array}{c}150 \frac{\varepsilon_{\mathrm{p}}\left(1-\varepsilon_{\mathrm{f}}\right) \mu_{\mathrm{f}}}{\varepsilon_{\mathrm{f}} d_{\mathrm{p}}^{2}}+1.75 \frac{\varepsilon_{\mathrm{p}} \rho_{\mathrm{f}}\left|\mathbf{u}_{\mathrm{f}}-\mathbf{u}_{\mathrm{p}}\right|}{d_{\mathrm{p}}}, \varepsilon_{\mathrm{f}} \leq 0.8 \\ \frac{3}{4} C_{\mathrm{D} 0} \frac{\varepsilon_{\mathrm{p}} \varepsilon_{\mathrm{f}} \rho_{\mathrm{f}}\left|\mathbf{u}_{\mathrm{f}}-\mathbf{u}_{\mathrm{p}}\right|}{d_{\mathrm{p}}} \varepsilon_{\mathrm{f}}^{-2.65}, \varepsilon_{\mathrm{f}}>0.8\end{array}\right.$

Drag coefficient of EMMS methods (EMMS/bubbling model and MSD-EMMS model):

$$
\beta_{\text {EMMS bubbling or MSD }}=\left\{\begin{array}{c}
\frac{150 \varepsilon_{\mathrm{p}}\left(1-\varepsilon_{\mathrm{f}}\right) \mu_{\mathrm{f}}}{\varepsilon_{\mathrm{f}} d_{\mathrm{p}}^{2}}+\frac{1.75 \varepsilon_{\mathrm{p}} \rho_{\mathrm{f}}\left|\mathbf{u}_{\mathrm{f}}-\mathbf{u}_{\mathrm{p}}\right|}{d_{\mathrm{p}}}, \varepsilon_{\mathrm{f}} \leq \varepsilon_{\mathrm{mf}} \\
H_{\mathrm{d}} \cdot \frac{3}{4} \frac{C_{\mathrm{D} 0} \varepsilon_{\mathrm{p}} \varepsilon_{\mathrm{f}} \rho_{\mathrm{f}}\left|\mathbf{u}_{\mathrm{f}}-\mathbf{u}_{\mathrm{p}}\right| \varepsilon_{\mathrm{f}}^{-2.65}}{d_{\mathrm{p}}}, \varepsilon_{\mathrm{mf}} \leq \varepsilon_{\mathrm{f}}<\varepsilon_{\mathrm{d}} \\
\frac{3}{4} \frac{C_{\mathrm{D} 0} \varepsilon_{\mathrm{p}} \varepsilon_{\mathrm{f}} \rho_{\mathrm{f}}\left|\mathbf{u}_{\mathrm{f}}-\mathbf{u}_{\mathrm{p}}\right| \varepsilon_{\mathrm{f}}^{-2.65}}{d_{\mathrm{p}}}, \varepsilon_{\mathrm{f}}>\varepsilon_{\mathrm{d}}
\end{array}\right.
$$


The relative error $(R E)$ between experimental and numerical results of the MSD-EMMS model is calculated, which can be seen in Table S 2 . The relative difference of bubble velocity for the corresponding bubble diameter is within $30 \%$ except for the $d_{\mathrm{b}}=24.4 \mathrm{~mm}$ at $U_{\mathrm{f}}=0.050 \mathrm{~m} / \mathrm{s}$. A fewer large bubbles are generated at low gas inlet velocities $\left(U_{\mathrm{f}}=0.050 \mathrm{~m} / \mathrm{s}\right)$, which results in a large gap between experimental and numerical results. In general, the simulated results of bubbles indicate a fair performance of prediction.

Table S 2. Relative error (RE) between experimental and numerical results of MSD-EMMS

\begin{tabular}{|c|c|c|c|c|c|c|c|c|}
\hline \multirow[t]{2}{*}{$U_{\mathrm{f}}$} & \multicolumn{2}{|c|}{$0.050 \mathrm{~m} / \mathrm{s}$} & \multicolumn{2}{|c|}{$0.061 \mathrm{~m} / \mathrm{s}$} & \multicolumn{2}{|c|}{$0.070 \mathrm{~m} / \mathrm{s}$} & \multicolumn{2}{|c|}{$0.083 \mathrm{~m} / \mathrm{s}$} \\
\hline & $d_{\mathrm{b}}(\mathrm{mm})$ & $R E$ & $d_{\mathrm{b}}(\mathrm{mm})$ & $R E$ & $d_{\mathrm{b}}(\mathrm{mm})$ & $R E$ & $d_{\mathrm{b}}(\mathrm{mm})$ & $R E$ \\
\hline & 5.34 & 0.027 & 5.96 & 0.057 & 6.93 & 0.30 & 5.94 & 0.20 \\
\hline & 7.47 & 0.0022 & 9.97 & 0.10 & 13.11 & 0.093 & 9.65 & 0.27 \\
\hline & 11.51 & 0.065 & 17.62 & 0.072 & 17.4 & 0.21 & 11.80 & 0.21 \\
\hline & 16.45 & 0.33 & 32.15 & 0.015 & 19.57 & 0.060 & 16.97 & 0.15 \\
\hline & 20.2 & 0.25 & & & 26.40 & 0.21 & 24.56 & 0.21 \\
\hline & 24.4 & 0.69 & & & & & 34.65 & 0.31 \\
\hline
\end{tabular}




\section{Reference}

1. Crowe, C. T.; Schwarzkopf, J. D.; Sommerfeld, M.; Tsuji, Y., Multiphase flows with droplets and particles. 2nd ed.; CRC Press: Boca Raton, FL, 2011; p 57-110.

2. Davidson, J.; Harrison, D., Fluidized Particles, Cambridge University Press. Cambridge, London 1963.

3. Shen, L.; Johnsson, F.; Leckner, B., Digital image analysis of hydrodynamics two-dimensional bubbling fluidized beds. Chemical Engineering Science 2004, 59, (13), 2607-2617.

4. Lu, Y.; Zhao, L.; Han, Q.; Wei, L.; Zhang, X.; Guo, L.; Wei, J., Minimum fluidization velocities for supercritical water fluidized bed within the range of $633-693 \mathrm{~K}$ and $23-27 \mathrm{MPa}$. International Journal of Multiphase Flow 2013, 49, 78-82.

5. Cranfield, R. R.; Geldart, D., Large particle fluidisation. Chemical Engineering Science 1974, 29, (4), 935-947.

6. Busciglio, A.; Vella, G.; Micale, G.; Rizzuti, L., Experimental analysis of bubble size distributions in 2D gas fluidized beds. Chemical Engineering Science 2010, 65, (16), 4782-4791.

7. Darton, R.; Rd, L.; Jf, D.; D, H., Bubble Growth Due To Coalescence in Fluidized Beds. Transactions of the Institution of Chemical Engineers 1977, 55, 274-280.

8. Cammarata, L.; Lettieri, P.; Micale, G.; Colman, D., 2D and 3D CFD Simulations of Bubbling Fluidized Beds Using Eulerian-Eulerian Models. International Journal of Chemical Reactor Engineering - INT J CHEM REACT ENG 2003, 1.

9. Wang, H.; Lu, Y.; Xi, K., Bubble behavior in gas-solid bubbling fluidized beds based on EMMS model: Comparison of 2D, Q2D, and 3D simulations. Chemical Engineering Research and Design 2019, 149, 65-80. 